\title{
Gallstone ileus: Rare Entity for Mechanical Small Bowel Obstruction
}

\author{
Kiran R.S. ${ }^{1}$, Sarmukh S. ${ }^{1}$ and Azmi H. ${ }^{1}$ \\ Department of General Surgery, Hospital Sultan Haji Ahmad Shah, Temerloh, Malaysia.
}

*Corresponding Author: Kiran R.S, Department of General Surgery, Hospital Sultan Haji Ahmad Shah, Temerloh, Malaysia.

Received date: July 27, 2021; Accepted date: August 10, 2021; Published date: September 30, 2021

Citation: Kiran R.S., Sarmukh S. and Azmi H. (2021) Gallstone ileus: Rare Entity for Mechanical Small Bowel Obstruction. J, Surgical Case Reports and Images 5(2); DOI: 10.31579/2690-1897/088

Copyright: (C) 2021, Kiran R.S., This is an open access article distributed under the Creative Commons Attribution License, which permits unrestricted use, distribution, and reproduction in any medium, provided the original work is properly cited.

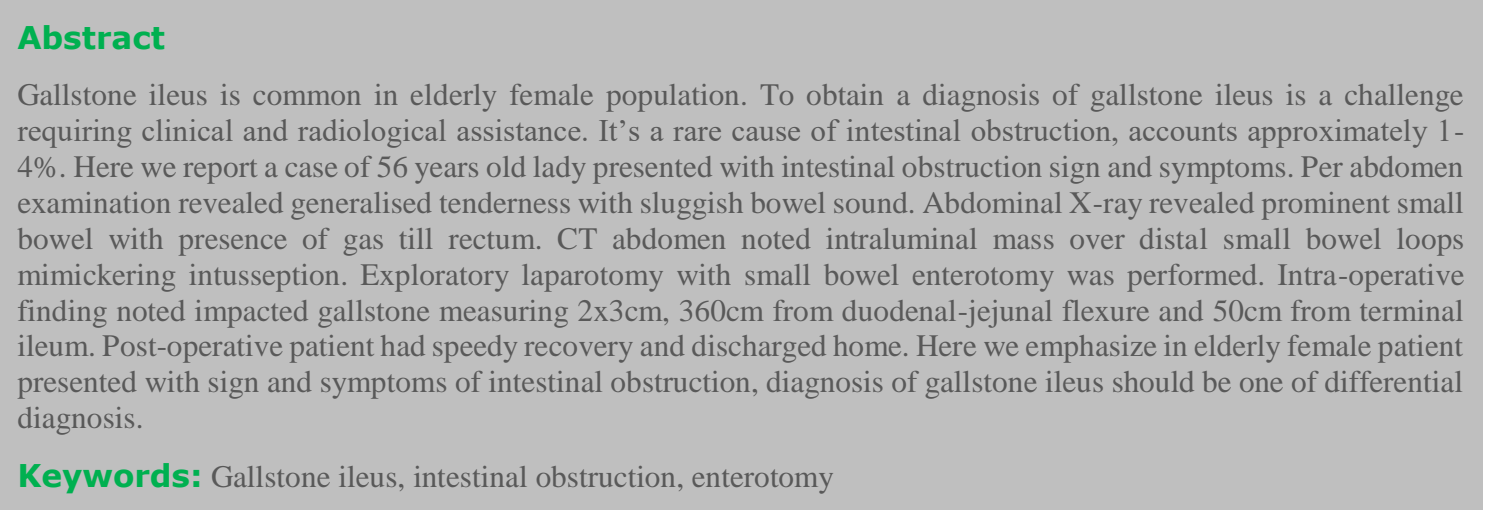

\section{Introduction}

Gallstone ileus was first introduced by Bartholin in 1654. He also mentioned it can lead to mechanical obstruction with gastrointestinal tract. It accounts for 1-4\% of all causes of mechanical obstruction, more common in female population 65 years old above and female to male ratio 3.5-6:1 [1-4]. In cases of misdiagnosis or delayed in obtaining diagnosis, morbidity and mortality is high [5]. Therefore, an early diagnosis and treatment can minimise morbidity and mortality rate as what we did for our patient.

\section{Case Report}

56 years old lady with underlying diabetes mellitus presented with abdominal pain (generalised, colicky in nature) with no bowel output for 2 days duration, associated with vomiting, reduce oral intake and lethargy. Per abdomen examination was generalised tenderness, bowel sound sluggish, hernia orifice was intact. Per rectal examination no abnormality was detected. Chest X-ray revealed no air under diaphragm and abdominal X-ray showed prominent small bowel with presence of gas till rectum. Proceeded with ultrasound of abdomen showed no evidence of collection. In view clinical finding did not correlate with imaging, we requested for $\mathrm{CT}$ abdomen which concluded as paralytic ileus caused by intraluminal mass over distal small bowel loops (differential diagnosis include gallstone ileus, bezoar ingestion or intussusception) (Figure $1 \&$ 2). Proceeded with exploratory laparotomy, small bowel enterotomy and peritoneal washout. Intra-operative finding revealed impacted stone $360 \mathrm{~cm}$ from duodenal-jejunal flexure, $50 \mathrm{~cm}$ from terminal ileum. Upon enterotomy noted pigmented gallstone $2 \times 3 \mathrm{~cm}$ (Figure $3 \& 4$ ), rest were normal. Patient recovered well and was discharge home. Patient was subsequently reviewed in out outpatient clinic, was well with no complain and unremarkable clinical finding and was discharged from our follow up. 


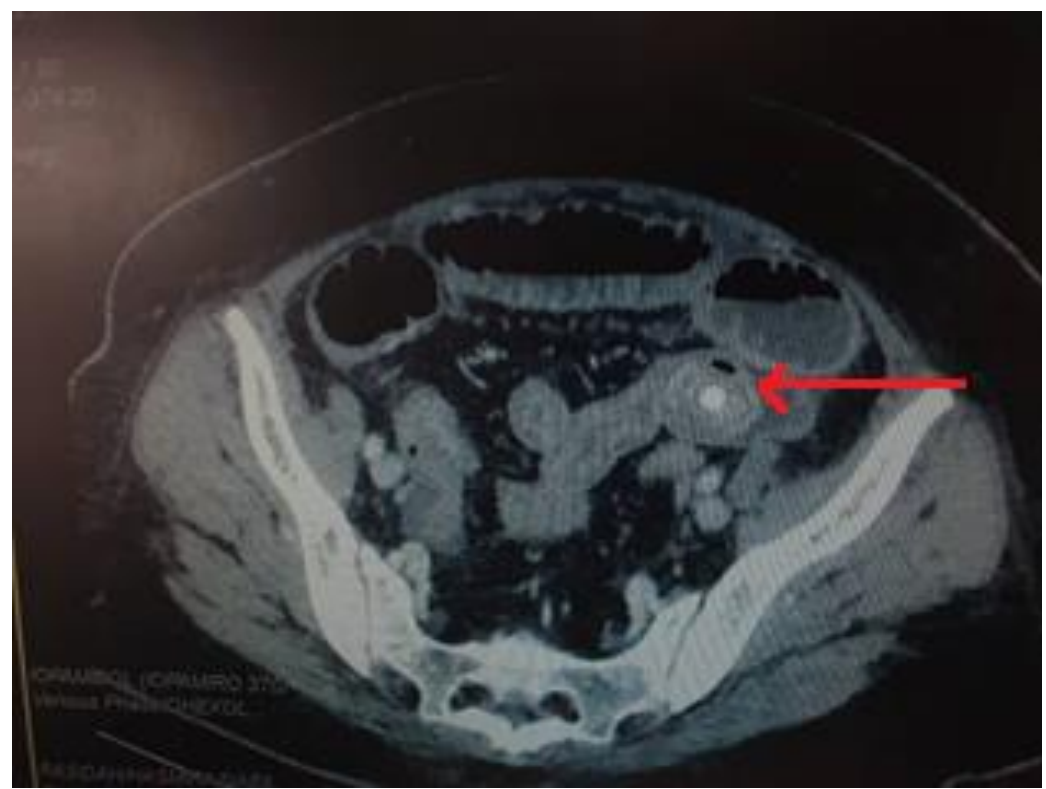

Figure 1. CT abdomen presence of intraluminal mass

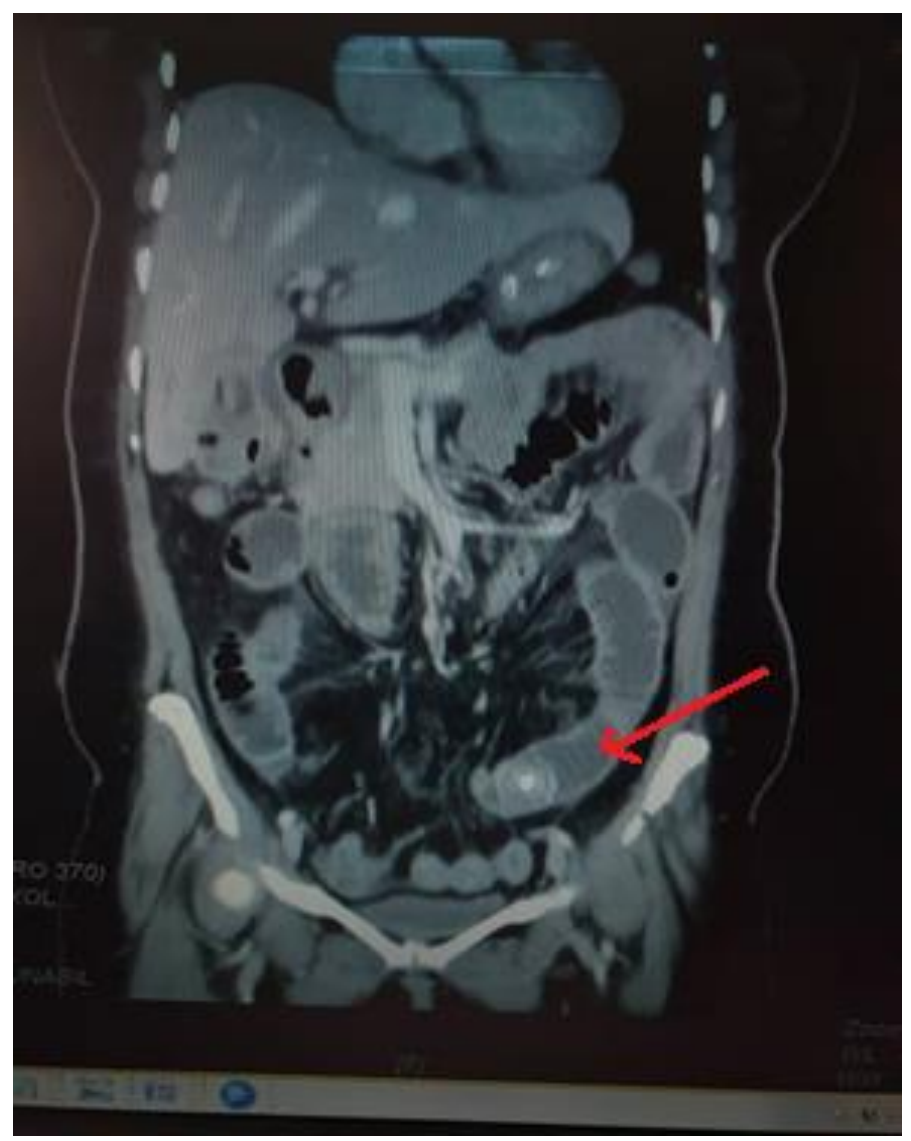

Figure 2. CT abdomen (coronal view) presence of intraluminal mass 


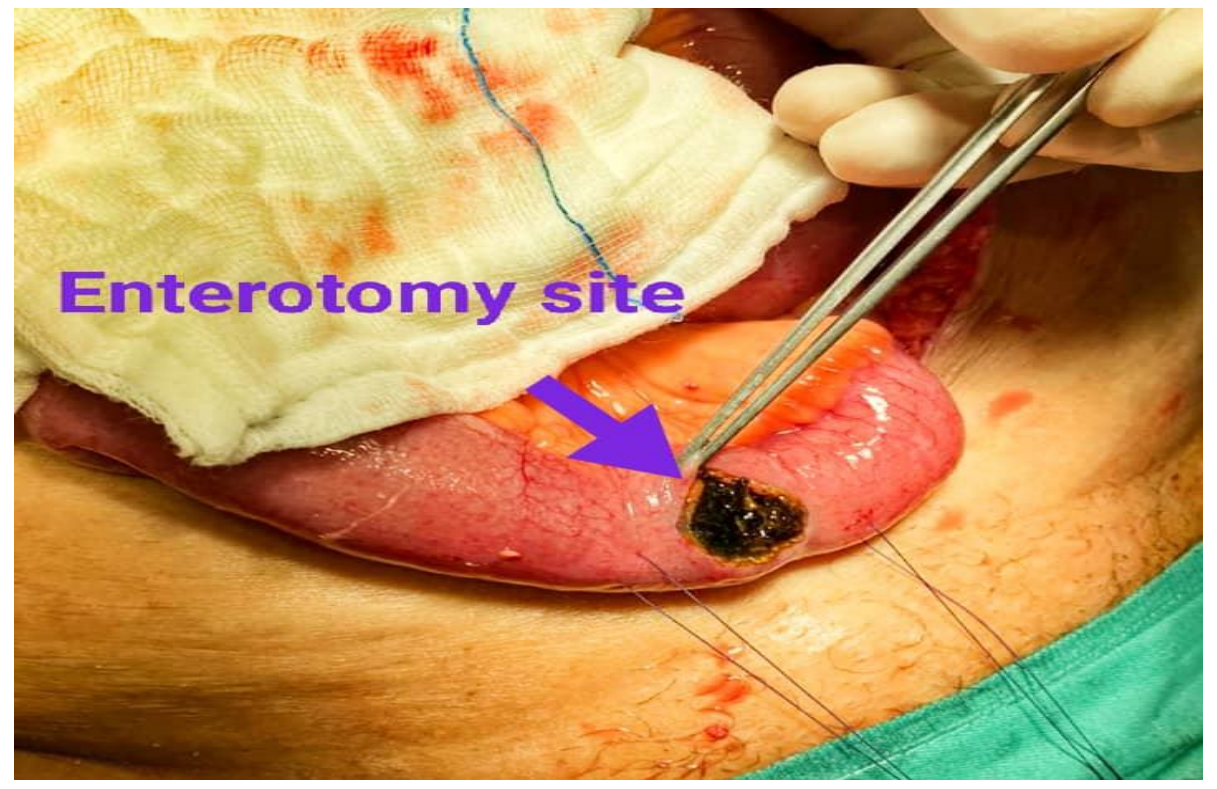

Figure 3. Upon enterotomy evidence of pigmented gallstone

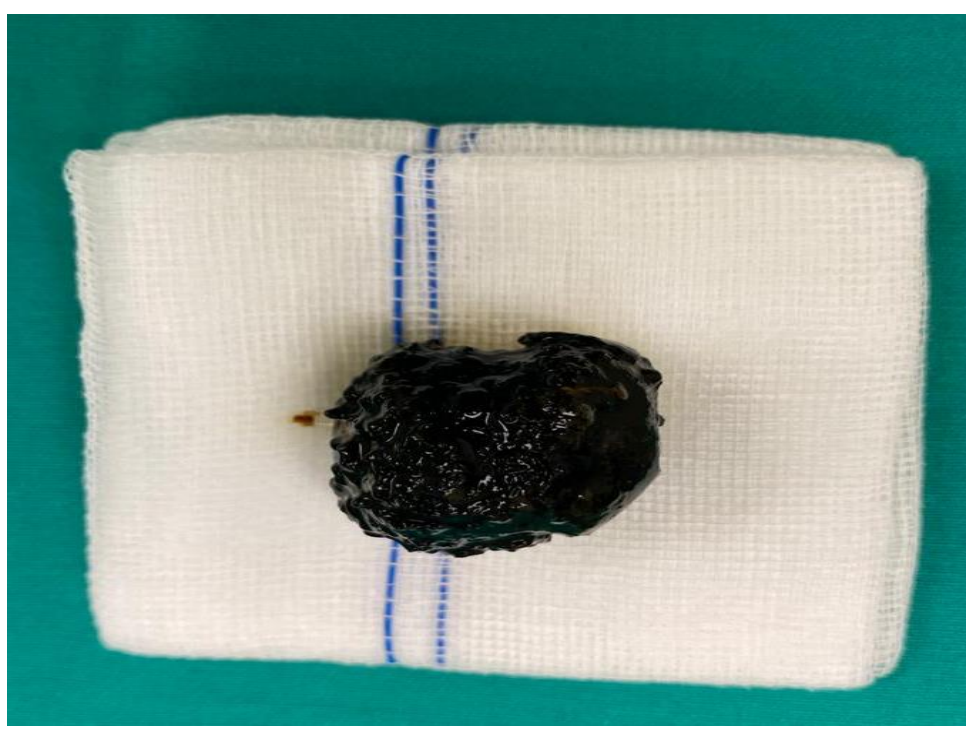

Figure 4. Pigmented gallstone

\section{Discussion}

Common cause of mechanical small bowel obstruction are adhesions and hernias, other causes include tumour. Rarer causes are caused by intraluminal obstruction which can be due to intussusception, gallstone ileus or foreign bodies [6]. Gallstone ileus is defined by obstruction of small bowel caused by gallstone. Pathophysiology of how it takes place is via fistula communication between inflamed gallbladder and gastrointestinal tract. Common location of gallstone impaction is over terminal ileum and ileocaecal valve as described by Reisner and Cohen, where a study was done on 1,001 cases and identified these 2 locations [3]. This common location of impaction is due to its diameter and reduce peristalsis activity. Other uncommon location for impaction is jejunum, ligament of Treitz, stomach, duodenum and colon [3]. Clinical manifestation can vary, commonly presented as sign and symptoms of intestinal obstruction. During physical examination, we can reveal abdominal tenderness, distention with diminished bowel sounds [2]. Biochemical markers are not specific for diagnosis. To confirm diagnosis of gallstone ileus, computed tomography imaging is the best modality as described by Leo George Rigler in 1941 which includes mechanical obstruction, pneumobilia and gallstone within bowel lumen [7]. Computed tomography imagingalso enables for decision making strategy and surgical planning [8]. Treatment of choice can be divided into surgical and non-surgical. Surgical treatment, the preferred operation is enterotomy and removal of stone [9]. Non-surgical intervention depends on location of obstruction which include endoscopic removal and shockwave lithotripsy [10]. Prognostic factor is poor for patient with advanced age, delayed in making diagnosis and concomitant medical illness. In our patient, early diagnosis and intervention played a great role in her recovery.

\section{Conclusion}

Gallstone ileus is a rare cause of mechanical small bowel obstruction. In patient presented with intestinal obstruction, we should always bear in mind this as one of the causes. Prompt diagnosis and treatment play a great role in survival. 


\section{References}

1. Kurtz RJ, Heimann TM, Kurtz AB: (1983) Gallstone ileus: a diagnostic problem. Am J Surg, 146: 314-317.

2. Clavien PA, Richon J, Burgan S, Rohner A: (1990) Gallstone ileus. Br J Surg, 77: 737-742.

3. Reisner RM, Cohen JR: (1994) Gallstone ileus: a review of 1,001 reported cases. Am Surg, 60: 441-446.

4. Rodríguez Hermosa JI, Codina Cazador A, Gironès Vilà J, Roig García J, Figa Francesch M, Acero Fernández D: (2001) Gallstone ileus: results of analysis of a series of 40 patients (in Spanish). Gastroenterol Hepatol, 24: 489-494.

5. Lobo DN, Jobling JC, Balfour TW: (2000) Gallstone ileus: diagnostic pitfalls and therapeutic successes. $J$ Clin Gastroenterol, 30: 72-76.
6. Harris J, Evers M: Small intestine; in Townsend C, Beauchamp RD, Evers B, Mattox K (eds): (2016) Sabiston Textbook of Surgery, ed 20. Philadelphia, Elsevier Saunders, chapt 49

7. Sahsamanis G, Maltezos K, Dimas P, Tassos A, Mouchasiris C: (2016) Bowel obstruction and perforation due to a large gallstone. A case report. Int J Surg Case Rep, 26: 193-196.

8. Yu CY, Lin CC, Shyu RY, et al: (2005) Value of CT in the diagnosis and management of gallstone ileus. World $J$ Gastroenterol, 11: 2142-2147.

9. Halabi WJ, Kang CY, Ketana N, et al: (2014) Surgery for gallstone ileus: a nationwide comparison of trends and outcomes. Ann Surg, 259: 329-335.

10. Dumonceau JM, Delhaye M, Devière J, Baize M, Cremer M: (1997) Endoscopic treatment of gastric outlet obstruction caused by a gallstone (Bouveret's syndrome) after extracorporeal shockwave lithotripsy. Endoscopy, 29: 319-321.
This work is licensed under Creative Commons Attribution 4.0 License

\section{To Submit Your Article Click Here: Submit Manuscript}

DOI: $10.31579 / 2690-1897 / 088$
Ready to submit your research? Choose Auctores and benefit from:

* fast, convenient online submission

* rigorous peer review by experienced research in your field

* rapid publication on acceptance

* authors retain copyrights

* unique DOI for all articles

* immediate, unrestricted online access

At Auctores, research is always in progress.

Learn more auctoresonline.org/journals/journal-of-surgical-case-reportsand-images 